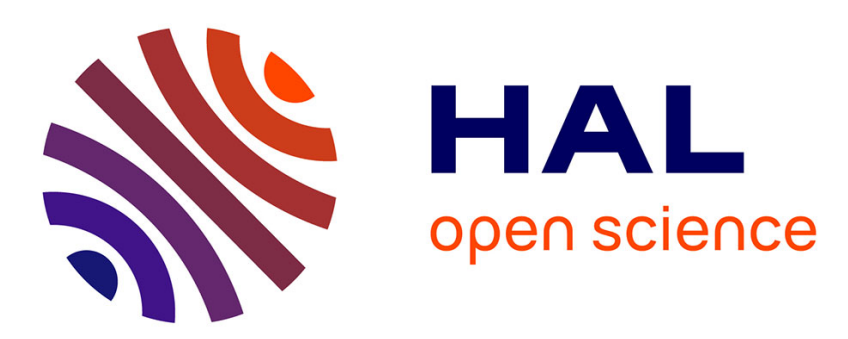

\title{
Field application of close-range digital photogrammetry (CRDP) for grain-scale fluvial morphology studies
}

\author{
Stéphane Bertin, Heide Friedrich
}

\section{To cite this version:}

Stéphane Bertin, Heide Friedrich. Field application of close-range digital photogrammetry (CRDP) for grain-scale fluvial morphology studies. Earth Surface Processes and Landforms, 2016, 41 (10), pp.1358 - 1369. 10.1002/esp.3906 . hal-03470772

\section{HAL Id: hal-03470772 \\ https://hal.science/hal-03470772}

Submitted on 21 Dec 2021

HAL is a multi-disciplinary open access archive for the deposit and dissemination of scientific research documents, whether they are published or not. The documents may come from teaching and research institutions in France or abroad, or from public or private research centers.
L'archive ouverte pluridisciplinaire HAL, est destinée au dépôt et à la diffusion de documents scientifiques de niveau recherche, publiés ou non, émanant des établissements d'enseignement et de recherche français ou étrangers, des laboratoires publics ou privés. 


\section{Field application of close-range digital 2 photogrammetry (CRDP) for grain- 3 scale fluvial morphology studies}

5 Stephane Bertin and Heide Friedrich, Department of Civil and Environmental 6 Engineering, The University of Auckland, Auckland, New Zealand.

7

8 Corresponding author: S. Bertin, Department of Civil and Environmental 9 Engineering, The University of Auckland, Auckland, New Zealand 10 (s.bertin@ymail.com).

\section{Abstract (up to 300 words)}

12 In situ measurement of grain-scale fluvial morphology is important for studies on grain roughness, sediment transport and the interactions between animals and the geomorphology, topics relevant to many river practitioners. Close-range digital photogrammetry (CRDP) and terrestrial laser scanning (TLS) are the two most common techniques to obtain high-resolution digital elevation models (DEMs) from fluvial surfaces. However, field application of topography remote sensing at the grain scale is presently hindered mainly by the tedious workflow challenges that one needs to overcome to obtain high-accuracy elevation data. A recommended approach for CRDP to collect high-resolution and high-accuracy DEMs has been developed for gravel-bed flume studies. The present paper investigates the deployment of the laboratory technique on three exposed gravel bars in a natural 23 river environment. In contrast to other approaches, having the calibration carried out 24 in the laboratory removes the need for independently surveyed ground-control 
25 targets, and makes for an efficient and effective data collection in the field. 26 Optimisation of the gravel-bed imagery helps DEM collection, without being impacted

27 by variable lighting conditions. The benefit of a light-weight 3D-printed gravel-bed 28 model for DEM quality assessment is shown, and confirms the reliability of grain 29 roughness data measured with CRDP. Imagery and DEM analysis evidences 30 sedimentological contrasts between gravel bars within the reach. The analysis of the surface elevations shows the effect variable grain-size and sediment sorting have on the surface roughness. By plotting the $2 \mathrm{D}$ structure functions and surface slopes and aspects we identify different grain arrangements and surface structures. The

34 calculation of the inclination index allows determining the surface-forming flow direction(s). We show that progress in topography remote sensing is important to extend our knowledge on fluvial morphology processes at the grain scale, and how a

37 technique customised for use by fluvial geomorphologists in the field benefits this 38 progress.

\section{Keywords (5)}

40 Field work; Gravel-bed river; Photogrammetry; DEM; Grain roughness

\section{1. Introduction}

42 Studies on the geomorphology of gravel-bed rivers at the grain scale and the 43 measurement of gravel patches have seen a growing interest over the last decades, 44 due to progress in high-resolution remote sensing. Digital elevation models (DEMs), analysed using the standard deviation of bed elevations, can potentially replace 46 tedious sediment sampling in the field and improve grain-roughness 47 parameterisation needed for hydraulic and sediment transport calculations (Aberle 
and Smart, 2003; Entwistle and Fuller, 2009; Heritage and Milan, 2009; Nikora et al., 1998). Likewise, collection of high-resolution DEMs from distinct hydraulic biotopes (e.g. riffles and pools, or bars and pools, exposed at the time of measurement) was

51 critical in characterising the links between morphological units, sediment transport and surface structure (Hodge et al., 2009a; Hodge et al., 2013) and to quantify the "patchy" nature of gravel surfaces (Nelson et al., 2010). With only traditional field sampling of surface composition, crucial information on particle exposure, imbrication and surface roughness cannot be derived. Measuring microtopographic relief is also important as it provides means to assess aquatic habitats and the relation between species and the geomorphology (Du Preez and Tunnicliffe, 2012; Hannam and Moskal, 2015; Rice et al., 2012).

Close-range digital photogrammetry (CRDP), i.e. the combination of using one or more digital cameras and subsequent image matching to obtain surface elevations at

61 the image overlap, and "time-of-flight" terrestrial laser-scanning (TLS), are presently 62 the most commonly used remote-sensing techniques, able to measure gravel-bed 63 topography with a sufficient amount of detail at the grain scale (spatial resolution $\sim \mathrm{mm}$ ). Both techniques have been used in both laboratory and field settings, and have been shown capable of measuring shallow riverbed microtopography (Bertin et al., 2013; Butler et al., 2002; Smith et al., 2012; Smith and Vericat, 2013). However, 67 the latter is seldom used, mainly due to degraded DEM quality compared to conventional in-air measurement. In addition, this application comes with substantial experimental difficulties. Generally, studied surfaces are exposed gravel bars at low flow or in drained laboratory flumes. When it comes to field applications, various

71 methodological attributes may be considered to decide which technique to adopt.

72 The most important aspect is the need to obtain fit-for-purpose topography data, 
73 which are suitable for the intended analysis. In other words, what is a sufficient

74 measurement accuracy and precision to improve our knowledge of fluvial

75 microtopography? For measuring fluvial surfaces at the grain scale, both CRDP and

76 TLS methodologies require the greatest care to mitigate errors in elevation data

77 (Bertin et al., 2015; Hodge et al., 2009b), errors which otherwise may affect findings

78 (James et al., 2007; Lane et al., 2005). Repeating scans, in addition to applying 79 erroneous points filtering techniques (Hodge et al., 2009b), is currently the best 80 option to reduce errors and improve accuracy for TLS applications, with the 81 measuring precision otherwise being dependent on the used instrument and 82 software. The challenge with CRDP is the development of a stable workflow from 83 image acquisition to surface structure data (Chandler et al., 2005; Lane, 2000; Lane 84 et al., 2000; Wackrow et al., 2007). Presently, a variety of DEM reconstruction techniques are available, from the now conventional digital stereo (i.e. two-camera) photogrammetry, using either commercial (Bird et al., 2010; Butler et al., 2002;

87 Chandler et al., 2005; Lane, 2000; Lane et al., 2000) or non-proprietary (Bertin et al., 88 2013; Bertin et al., 2014; Bertin et al., 2015; Bouratsis et al., 2013) calibration and stereo-matching engines, to novel structure-from-motion (SfM) or multi-view stereo (MVS) photogrammetry (Fonstad et al., 2013; James and Robson, 2012; Javernick et al., 2014), which does not need calibration but has not been tested on a gravel

92 patch yet. Recent progress was made in the laboratory, showing that the use of non93 proprietary digital stereo photogrammetry optimises the workflow, which when done appropriately, can result in sub-millimetre accurate gravel-bed DEMs (Bertin et al., 2015) - a development that is yet to be tested in a natural river environment. Compared to applying CRDP in the laboratory, the ease with which data are 97 collected in the field is also becoming more important, in addition to the quality of 
obtained data. A well-developed CRDP system has the advantage of being easily deployed in the field due to its reduced cost, its small size and weight, its optional power supply and the possibility of very quick data collection (Bird et al., 2010; Javernick et al., 2014; Lane, 2000; Rieke-Zapp et al., 2009).

102 Despite the wealth of available photogrammetric solutions, and the possibility to 103 provide a lightweight and very accurate surveying equipment customised for use by earth scientists, "potential photogrammetric users continue to have reservations about its potential and often consider its field use to be too complicated" (Rieke-Zapp et al., 2009). In response, this paper presents an example of how CRDP can be

107 used in the field to collect information on fluvial microtopography efficiently and 108 effectively. We tested a recently developed non-proprietary CRDP technique (Bertin 109 et al., 2015), for which the imaging system relies on two consumer-grade digital cameras, in a field environment, measuring exposed gravel bars at the grain scale. A 111 small meandering gravel-bed river in New Zealand was the location for the tests. 112 Imagery data were collected at three distinct gravel bars, allowing testing in a variety 113 of sediment size and surface structure settings. A ground-truth object was used on site to assess the accuracy of obtained elevation data, generally performed in other studies using an independent measuring device. CRDP readily produced submillimetre resolution and accuracy DEMs, without the need to deploy control targets

117 on the riverbed for calibration. Using CRDP has the advantage that calibration of the 118 cameras can be carried out in the laboratory before going to the field. We show that 119 by doing so, DEM collection is not affected negatively with test undertaken on the field site. Information derived from the CRDP data was adequate to monitor surface

121 roughness, grain size and 3D arrangement. Ultimately, this allowed examination of 122 the sedimentological contrasts between bars within the reach. 


\section{Methodology}

124 2.1. Study site: the Whakatiwai river

125 Field data were collected from the Whakatiwai river (Figure 1A), located in the

126 North Island of New Zealand ( $\left.37^{\circ} 05^{\prime} \mathrm{S}, 175^{\circ} 18^{\prime} \mathrm{E}\right)$, a small gravel-bed river flowing

127 over greywacke material and draining a watershed of $\sim 12 \mathrm{~km}^{2}$ (maximum elevation

128 c. $490 \mathrm{~m}$ amsl). The Whakatiwai is fed by numerous small streams originating from

129 the steep East-facing slopes of the Hunua Ranges, and flows to sea in a very short 130 distance, roughly ten kilometres from its source to the river mouth in the Firth of

131 Thames. On the valley floor, the Whakatiwai is a meandering river, with rapid

132 alluvium bank erosion during flood flows, which essentially transports cobbles (5-25

$133 \mathrm{~cm})$ and pebbles $(1-5 \mathrm{~cm})$, with occasional patches of sand/silt and small boulders

134 found along its bed. Because of its short span, there is no gravel-sand transition; the 135 riverbed remains gravelly all the way through to the river mouth. In terms of 136 hydrologic regime, the Whakatiwai is governed by flashy hydrographs and

137 competent flows during the autumn-spring season, with mostly low flows over the 138 summer months, during which gravel bars become vegetated. No flow gauging 139 exists for the river; hence flow data are unavailable for the site.

140 For the tests a $\sim 200 \mathrm{~m}$ long study reach was chosen, situated only hundred 141 meters upstream of the river mouth and comprising numerous well-defined gravel

142 bars adjacent to the eroding banks. Three exposed and vegetation-free gravel bars 143 were selected, covering a range of sediment size and surface structures. They were

144 labelled bar \#1 to \#3, with numbers increasing upstream. Within each bar, a small 145 area of exposed gravel $\left(\sim 0.5 \mathrm{~m}^{2}\right)$, termed "patch", was chosen at the bar head close 146 to the water edge, for consistency in the measurements, also ensuring the surfaces 147 studied are regularly water-worked. 
A
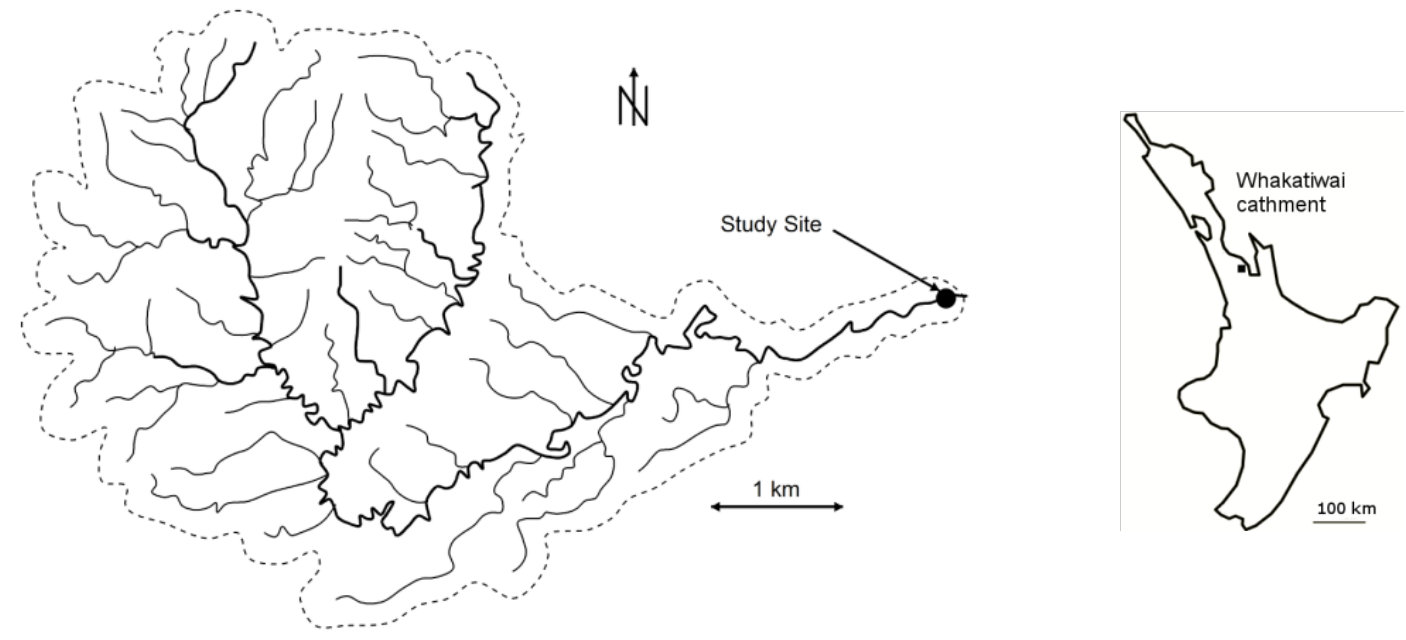

B

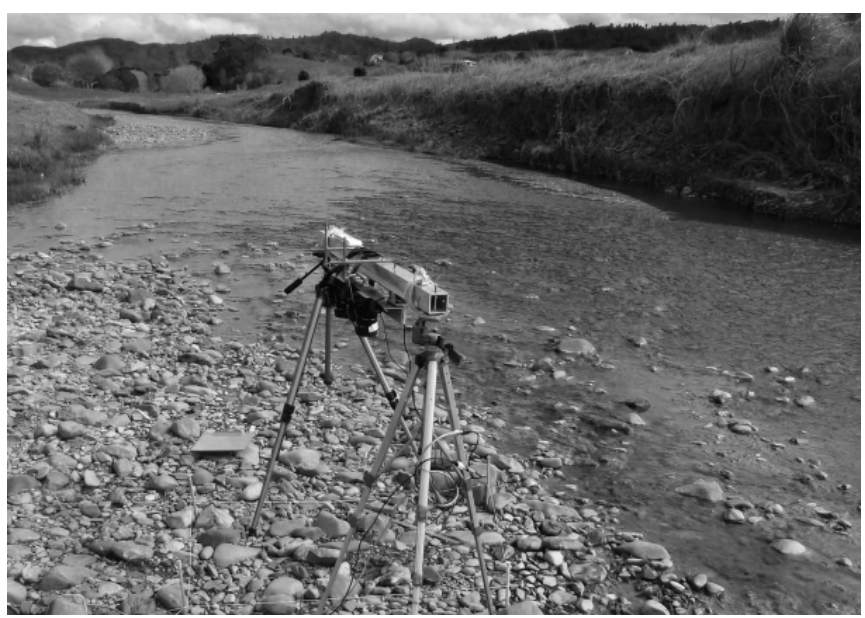

148 Figure 1. Whakatiwai catchment in the North Island of New Zealand, A) site location; and B) image of CRDP deployment on Bar \#2, looking upstream. Note the alignment of the setup with the apparent flow direction.

\subsection{CRDP deployment and field DEM collection}

152 Imagery data were collected from the three patches in August 2014, after an

153 extended period of dry weather, following a methodology developed in the laboratory

154 and presented in Bertin et al. (2015). The two cameras used in stereo (side-by-side, separated by a $250 \mathrm{~mm}$ baseline distance between the two optical centres) were

156 Nikon D5100s (16.2 Mpixel complementary metal oxide semiconductor (CMOS)

157 sensors) with Nikkor $20 \mathrm{~mm}$ lenses. The cameras, fully charged, were rigidly 158 attached on a $1.2 \mathrm{~m}$ long mounting bar that could be hanged horizontally (using a 
159 bubble level) above the riverbed using two tripods (Figure 1B). The setup (cameras, 160 tripods and mounting bar) weighed approximately $8 \mathrm{Kg}$.

161 Prior to transport to the field, the cameras' arrangement on the mounting bar was 162 carefully calibrated in the laboratory by recording stereo photographs (also called 163 stereoscopic images) of a flat chequerboard, and using Bouguet (2010)'s Matlab ${ }^{\circledR}$ 164 toolbox to determine the calibration parameters (readers should refer to Bertin et al. 165 (2015) for a complete description of the calibration process). The aperture was set to 166 $\mathrm{f} / 20$, ensuring a large depth of field, and focus was set at a distance of $0.8 \mathrm{~m}$, based on the expected field requirements. After calibration, care was taken to ensure that 168 the cameras' arrangement (i.e. relative rotation and translation) was not disturbed. 169 Subsequent testing in the field, after transport, confirmed that minimal disturbance 170 occured.

Whilst in the field, we attempted to orientate the mounting bar parallel to the 172 antecedent flow direction (Figure 1B), determined by eye from channel shape, 173 producing photographs and DEMs with $x$-axis values increasing downstream (e.g. 174 Figure 3). This later allowed to relate the measured bed properties to the local flow 175 direction. Stereo photographs of the exposed patches were recorded vertically, 176 reducing occlusions (i.e. shadowed areas that cannot be seen in one or the two 177 images) on the surface compared with oblique measurements, from a height of 178 approximately $0.8 \mathrm{~m}$, resulting in point data spacing (i.e. pixel size) $\sim 0.2 \mathrm{~mm}$ and a 179 theoretical depth resolution $\sim 0.6 \mathrm{~mm}$. Cameras were operated in manual mode, with 180 the possibility to vary the shutter speed to have well-illuminated and contrasted 181 photographs necessary for successful stereo matching (Bertin et al., 2015). Remote 182 control was possible by connecting the cameras to a laptop. 
Data processing consisted in rectifying the stereo photographs to epipolar 184 geometry using the calibration parameters, and transforming the images with the multi-scale Retinex algorithm in GIMP $^{\circledR}$, before pixel-to-pixel stereo matching using 186 Gimel'farb (2002)'s SDPS, providing point cloud data and ortho-images. Because the 187 SDPS algorithm matches corresponding points along lines of 1 pixel width, accurate 188 image rectification (hence accurate calibration) is essential to produce stereo photographs whose corresponding pixels are ideally on the same scanline (also called epipolar lines, i.e. same vertical position in a photograph). Doing so minimises the systematic matching errors due to calibration. Image transformation with Retinex 192 heightens the similarity between the two images forming a stereo photograph and 193 improves stereo-matching performance (Bertin et al., 2015), which is specifically 194 important in the field application lacking direct control over the illumination. From the 195 point cloud data, DEMs were interpolated onto regular grids with $1 \mathrm{~mm}$ spacing, first by interpolating onto $0.25 \mathrm{~mm}$ grids, consistent with the best resolution achievable, 197 to minimise the loss of topographic information (Bertin et al., 2014; Hodge et al., 198 2009b), then resampling onto the final grids to expedite calculations with minimal 199 surface smoothing (mean unsigned (absolute) error, MUE $\sim 0.025 \mathrm{~mm}$ and standard 200 deviation of error, SDE $\sim 0.035 \mathrm{~mm}$ between initial and resampled surfaces). Before 201 resampling onto a $1 \mathrm{~mm}$ grid, outliers were identified using the mean elevation 202 difference parameter (Hodge et al., 2009b), and replaced in the DEMs using bi-cubic 203 spline interpolation. Because the MUE between original and filtered DEMs 204 accounted for less than $0.01 \mathrm{~mm}$, filtering was considered optional and its application 205 was not stringent. 


\subsection{CRDP validation and field DEM accuracy}

207 CRDP data quality assessment was done in two ways, by (i) checking on site the 208 validity of the calibration performed in the laboratory prior to moving to the field; and 209 (ii) measuring a ground-truth object, to realistically determine the accuracy of the 210 field DEMs.

211 To ascertain the validity of the calibration performed in the laboratory, after 212 having transported the CRDP setup to the field, a small chequerboard $(0.3 \times 0.2 \mathrm{~m}$, $213 \sim 0.2 \mathrm{Kg}$, made of alternating black and white squares) was placed on the riverbed 214 and photographed in different positions, altogether covering the common field of 215 view (CFoV) between both cameras. The stereo photographs were rectified using 216 the calibration data obtained in the laboratory, and the rectification error, which is the 217 absolute scanline difference between corresponding pixels (Bertin et al., 2015; 218 Bradley and Heidrich, 2010), was measured for every square's corners in all rectified 219 stereo photographs of the chequerboard (i.e. at about 200 locations throughout the 220 measurement area). The mean, standard deviation, and maximum rectification error 221 were computed, and compared with values obtained before moving to the field.

222 Final DEM quality was assessed by measuring a 3D-printed gravel bed, specifically transported to the field, following the method of Bertin et al. (2014). The 224 use of this realistic ground-truth object of a water-worked gravel bed improves on 225 previous DEM assessment methods, traditionally requiring check points to be deployed on the riverbed and surveyed with a total station, to be able to compare with the measurements after co-registration of the two (Bouratsis et al., 2013; Butler et al., 1998; Lane, 2000; Lane et al., 2000), in terms of density/repartition of the

229 check points and registration errors, hence reliability of the assessment. We show 230 herewith that the field use of the 3D-printed gravel bed ground truth sped up and 
231 made DEM quality assessment easier. For the assessment, the 3D-printed gravel 232 bed model (296 x $184 \mathrm{~mm}, \sim 1.5 \mathrm{Kg}$, shown in Figure 4) was imaged with CRDP

233 besides gravel-bar microtopography (same camera distance of $0.8 \mathrm{~m}$ ). After DEM 234 reconstruction, measured elevations were aligned with the 'truth' elevations and 235 compared at more than 800,000 points, located every $0.25 \mathrm{~mm}$ on an orthogonal 236 grid, to realistically determine the field performance of CRDP in this work.

\section{2.4. DEM analysis and information on gravel-bar surface structure}

238 Before the DEMs were analysed, it was necessary to remove the combined effect of 239 the local bed slope and setup misalignment from the riverbed (i.e. non-parallelism), 240 which could obscure smaller grain-scale properties. In the absence of bedforms, 241 linear trend surfaces were removed from the DEMs using a least-squares fit 242 procedure (Aberle and Nikora, 2006; Cooper and Tait, 2009; Hodge et al., 2009a), 243 and DEMs were normalised to have a mean elevation equal to zero.

244 Analysis of gravel-bar topography and surface structure started with the 245 calculation of first-order moments of detrended bed elevations: the range $\left(\Delta_{z}\right)$, 246 standard deviation $\left(\sigma_{z}\right)$ and skewness $\left(S_{k}\right)$ were evaluated. The first two parameters 247 are surrogates of grain roughness parameters based on sediment size (Aberle and 248 Smart, 2003; Entwistle and Fuller, 2009; Heritage and Milan, 2009; Nikora et al., 249 1998). The bed elevation skewness is useful to determine if a gravel bed is water250 worked, in this case displaying positive values, contrasting with the negatively 251 skewed man-made screeded gravel beds (Aberle and Nikora, 2006). Generalised 2D 252 second-order structure functions (Nikora et al., 1998), similar to using 253 semivariograms, were used to estimate the correlations between detrended 254 elevations at different lags and in different directions. DEM analysis continued with 255 the evaluation of the slope and aspect angles of each of the $1 \mathrm{~mm}^{2}$ DEM grid cells 
256 (Hodge et al., 2009a), providing information on grain arrangement at the bar surface.

257 The last step in our investigation of DEM properties was the evaluation of the 258 inclination index, representing particle imbrication, which should be maximal in the 259 direction of the flow (Laronne and Carson, 1976), by analysing the signs of elevation 260 changes between successive pairs of DEM points at different lags and in different 261 directions, following the method presented in Millane et al. (2006). Information on 262 how to use these different statistical analysis methods applied to the DEMs is 263 introduced in detail in the references provided, and thus is not repeated herewith.

\subsection{Image analysis and information on bed-surface grain size and} 265 orientation

To complement information derived from the DEMs, grain-size distributions (GSDs) based on the sediment grains' intermediate $(b-)$ axis, and the grains' long (a-) axis 268 orientation, were determined using the image-analysis tool Basegrain $\circledast$, which allows 269 for automatic grain separation in digital pictures of gravel beds and applies Fehr's 270 (1987) line-sampling method for the results' analysis (Detert and Weitbrecht, 2012).

271 For each patch, a single photograph collected with CRDP was necessary.

272 In order to determine the bed-surface composition (and not the subsurface 273 composition, as per default), the percentage of non-detected fines at $10 \mathrm{~mm}$ was 274 changed from $25 \%$ to $10 \%$ during the results' analysis, as in Rüther et al. (2013). 275 Moreover, the ratio of image-detected $b$-axis (written $b^{\prime}$ ) and true $b$-axis, which 276 generally differs from unity due to particle burial, foreshortening and overlapping 277 (Graham et al., 2010), was adjusted to obtain GSDs comparable with GSDs obtained 278 by manual size-sieving. $b / b$ ' was calibrated by measuring gravels picked up along a 279 line on the riverbed with a digital calliper, and comparing the results with those obtained by Basegrain $®$. The best match was obtained using $b / b^{\prime}=1.19$, a value 
281 also reported from armour layers formed in a laboratory flume (Bertin and Friedrich,

282 Submitted). Grain orientation was automatically determined by fitting an ellipse, 283 whose areal normalised second-central moment equals that of the grain, and by 284 computing the angle formed between the ellipse long axis and the flow-orientated 285 image long axis.

\section{Field observations and analysis}

\subsection{Bed-surface grain size and orientation}

288 The three patches examined present large differences in sediment size at the bar 289 surface (Figures 2A and 3 ). The median sediment size $\left(D_{50}\right)$ varied between 18 and $29047 \mathrm{~mm}$; $D_{16}$ between 7 and $18 \mathrm{~mm}$; and $D_{90}$ between 27 and $104 \mathrm{~mm}$. The patch in 291 bar \#1 was the better sorted of the three patches, with a geometric standard 292 deviation $\sigma=\sqrt{D_{84} / D_{16}}=1.4$, compared with 2.2 and 2.4 for bar \#2 and bar \#3, 293 respectively. Grain-size variability between gravel bars in the same river reach is not 294 surprising (e.g. Hauer et al. (2014) and Verdú et al. (2005)). Grain-size variability 295 within bars was also recognised, with coarser material found at the bar head 296 compared to the bar tail ( $D_{50}$ increased by $30 \%$ in average, Rice and Church (2010)).

297 Despite that consistent patch selection at the bar head was not easily achieved in 298 practice, the between-bar grain-size differences observed in Figure 2A largely 299 exceed the in-bar variability observed by Rice and Church (2010), indicating a neat 300 grain-size difference between bars in the Whakatiwai that is not the result of 301 downstream fining only. It is assumed that this difference arises from a combination

302 of factors, such as the elevation of the patch with respect to the mean water-surface 303 level, the planform position of the gravel bar, consistent with competence 

305 banks.

A

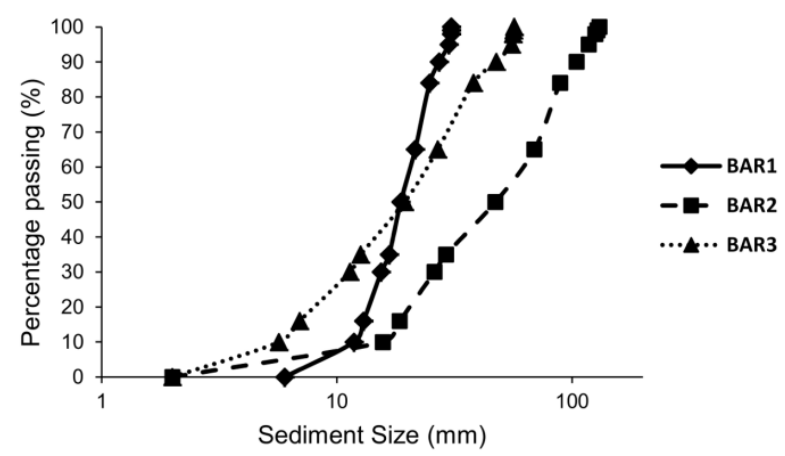

B

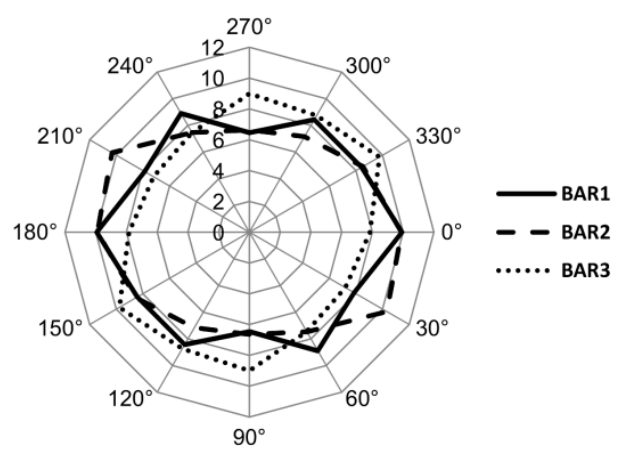

306 Figure 2. (A) Bed-surface grain-size distributions for the three Whakatiwai patches; and $(B)$ frequency-distribution of grains' a-axis (i.e. long axis) orientation with respect to the flow direction determined by eye in the field (from $0^{\circ}$ to $180^{\circ}$ ).

Grain orientation at the bed surface also differed between patches (Figure 2B $)$. For bar \#1, the bed material preferentially aligned its long axis parallel to the flow 311 direction. This preferential alignment of the grains with water-working, linked to an in312 situ reworking of grains in below entrainment threshold conditions, was observed 313 previously (Aberle and Nikora, 2006; Butler et al., 2001). For bar \#2, the same 314 preferential alignment of the grains was observed, but this time, the proportion of 315 grains forming a $30^{\circ}$ angle to the flow with their a-axis was as large as the proportion 316 of grains aligned parallel to the flow. This may suggest that the actual surface317 forming flow direction was somewhere between $0^{\circ}$ and $30^{\circ}$ with respect to the image 318 orientation. The latter analysis should be taken with caution however, as previous research showed that prevailing grain orientation is also influenced by the sediment transport mode, hence is an ambiguous descriptor of flow direction (Hodge et al., 321 2009a). For instance, coarse grains transported by rolling or sliding often come to 322 rest with their a-axis perpendicular to the flow direction (Laronne and Carson, 1976). 
323 Bar \#3 presents the largest proportion of grains aligned perpendicular to the 324 (assumed) flow direction. There are two possibilities to explain this tendency: the

325 flow direction was not correctly determined; or, more coarse grains were transported 326 by rolling or sliding during the last competent event(s) compared to the other 327 patches.

\subsection{Grain-scale DEMs and ortho-images}

329 CRDP naturally produces 2D (i.e. ortho-images) and 2.5D (i.e. DEMs) maps of the surfaces studied (Figure 3 ). In previous studies, visualisation of the ortho-images, and comparison with the DEMs, was considered an effective way of controlling 332 photogrammetric performance qualitatively (Butler et al., 1998; Lane, 2000). Since 333 visual inspection of the ortho-images obtained during this work show high quality 334 (Figure 3), without apparent mixed pixels and/or distortions, we can assume that stereo matching performed well for the entire measurement area.

Field studies using TLS also require imagery data to be collected, whether it is 337 for documenting (Heritage and Milan, 2009) and/or for grain-size analysis (Hodge et 338 al., 2009a). As CRDP data are obtained from imagery, both the DEMs and the ortho339 images are automatically referenced within the same coordinate system (Figure 3), 340 which saves the need to align the two.

\subsection{CRDP validation and DEM accuracy}

342 The rectification error just after calibration (i.e. in the laboratory) was represented by 343 a mean of 0.09 pixel, a standard deviation of 0.08 pixel and a maximum of 0.37 pixel, 344 ensuring minimal systematic error during stereo matching. After moving the CRDP 345 setup to the field, the rectification error increased (mean $=0.29$ pixel, standard 346 deviation $=0.23$ pixel and maximum $=0.91$ pixel), certainly caused by the transport 
347 (and shaking that occurred) in the car. It is noted that no particular measure was 348 taken to transport the setup; other than it being placed flat in the boot of the car,
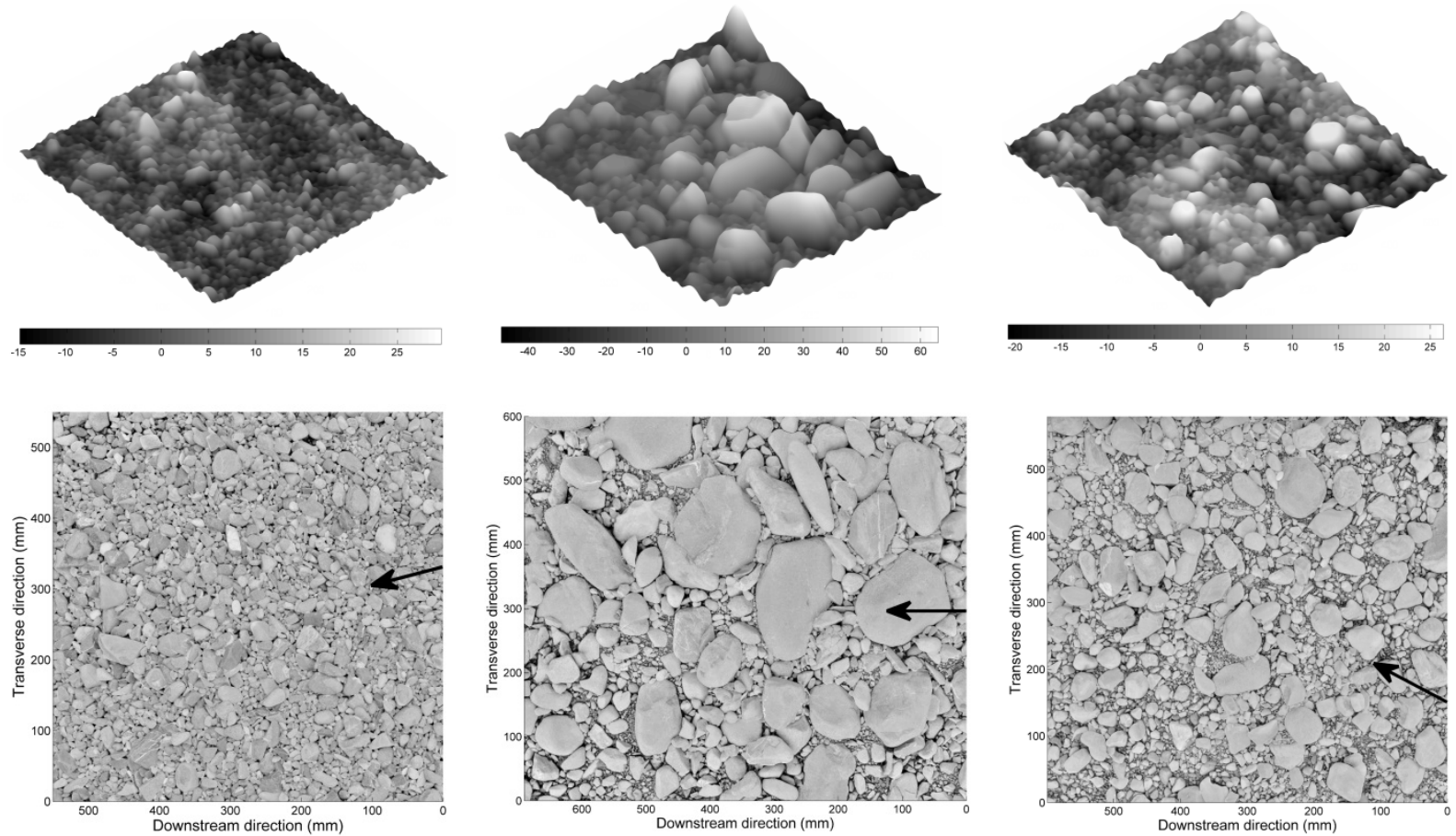

350 Figure 3. Final DEMs and ortho-images from the Whakatiwai patches (bar \#1 to \#3

351 from left to right). Elevation is represented as gradient of greys, and is in millimetres.

352 Flow direction, determined visually in the field, is from right to left. Arrows show the most probable flow direction (Figure 8).

soft material to protect the equipment and hinder any movement. Despite the increased rectification error, which naturally will affect stereo-matching performance, the rectification error remained below 1 pixel throughout the imaging area, the 357 threshold above which stereo-matching errors become inevitable, since the SDPS 358 stereo matching is performed along lines of 1 pixel width. In the case of significantly impacted camera arrangement, which would have prevented accurate image rectification, it would have been possible to re-calibrate on-site using the 
361 chequerboard (taking approximately 30 minutes), and/or upon return to the 362 laboratory given sufficient camera battery life.

363 Figure 4A shows the 3D-printed gravel-bed model used for in-situ DEM quality 364 assessment. The chequerboard was used to ensure that the 3D model was placed 365 as horizontal on the ground as possible, facilitating the numerical co-registration of 366 measured and truth data (Bertin et al., 2014). Figure 4C shows the DEM of 367 difference (DoD), obtained by differentiating the measured DEM of the 3D-printed 368 model (Figure 4B) with the truth DEM, after alignment of the two. Comparison was 369 done on a grid with $0.25 \mathrm{~mm}$ spacing; hence at more than 800,000 locations. 370 Visually, large errors (> $10 \mathrm{~mm}$ ) are rare and are essentially visible at the grains' 371 edges and the troughs of the surface. The measurement of occlusions is a well372 known difficulty for both CRDP and TLS (Bertin et al., 2015; Bouratsis et al., 2013; 373 Chandler et al., 2005; Hodge et al., 2009b). Consequently, a general reduction in 374 pore depth and DEM properties such as $\sigma_{z}$ is expected. Quantitatively, most of the 375 measured DEM points (98\%) were within $\pm 3 \mathrm{~mm}$ from the truth data, $82 \%$ were 376 within $\pm 1 \mathrm{~mm}$, and $58 \%$ were within $\pm 0.5 \mathrm{~mm} . \sigma_{z}$ measured from the DEM was $37799.8 \%$ of the truth value, showing that surface roughness is reliably measured. From 378 the DoD, a MUE of $0.67 \mathrm{~mm}$ between measured and truth values was estimated, 379 with a SDE of $1.16 \mathrm{~mm}$ and a maximum unsigned error of $17.1 \mathrm{~mm}$. This is not as 380 good as what can be achieved with CRDP in a laboratory setting (MUE $=0.43 \mathrm{~mm}$, $381 \mathrm{SDE}=0.62 \mathrm{~mm}$ and maximum unsigned error of $8.16 \mathrm{~mm}$ ), with a measuring 382 distance of $640 \mathrm{~mm}$ and a $250 \mathrm{~mm}$ baseline between the cameras (Bertin et al., 383 2014). We assume that the deterioration in field DEM quality compared with the 384 laboratory is essentially the result of the increased camera-to-object distance used 385 for image recording, hence degraded horizontal and depth measurement resolutions, 
and the increased rectification error due to transport. However, this evaluation shows 387 that CRDP can measure exposed fluvial surfaces in the field with sub-millimetre resolution and vertical accuracy (based on MUE), and guarantees reliable grainscale roughness information from the DEMs. CRDP can even outperform TLS, for

A

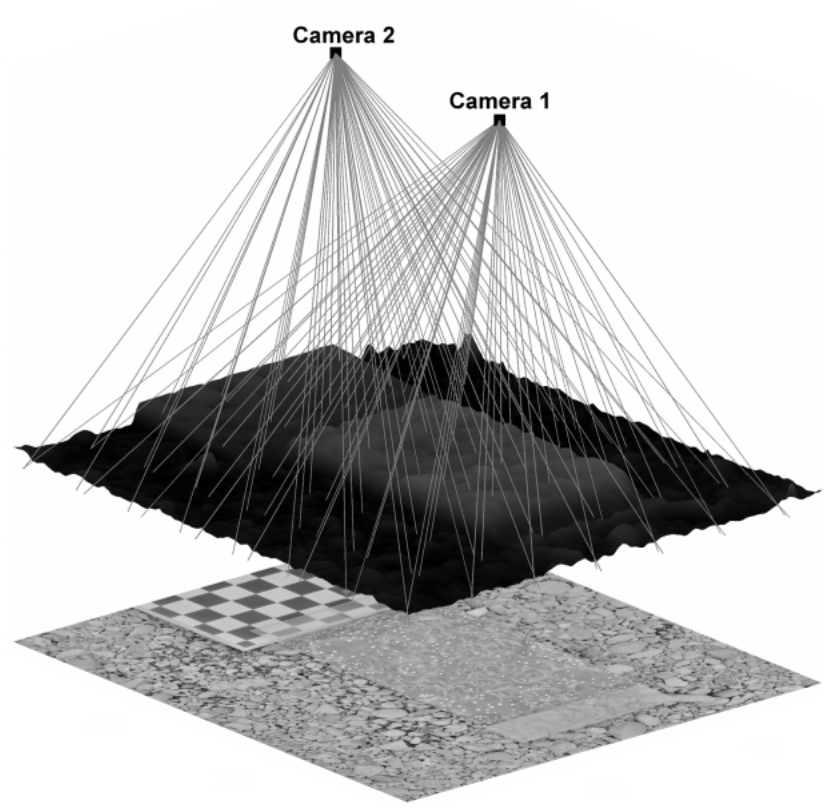

B

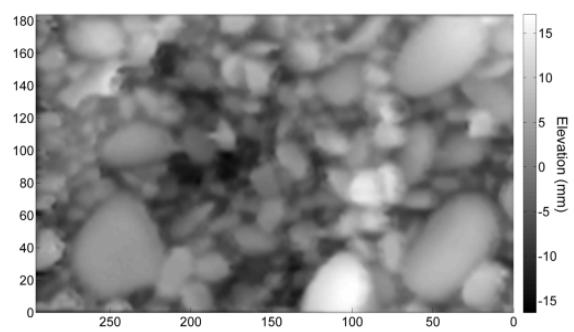

C

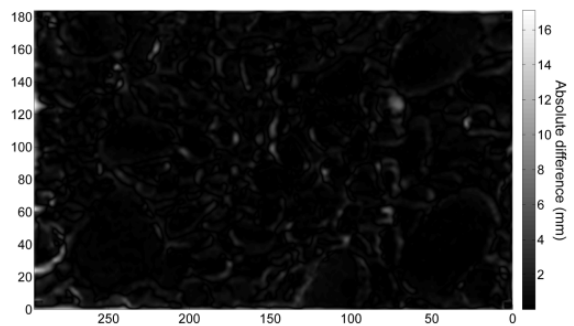

390 Figure 4. (A) Close-up presentation of on-site quantitative evaluation of CRDP 391 performance using a 3D-printed gravel-bed model; (B) measured DEM of the 3D392 printed model; and (C) DEM of difference (DoD) between measured and truth data 393 (0.25 $\mathrm{mm}$ sampling distance).

394 which a rigorous past application was constrained by the $4 \mathrm{~mm}$ laser footprint and 395 resulted in a minimum SDE of $\sim 1.3 \mathrm{~mm}$, after averaging three repeat scans of a 396 plane surface in the laboratory (Hodge et al., 2009b).

\subsection{DEM analysis}

398 Figure 5A shows the distribution of (detrended) bed elevations for the three patches. 399 All distributions are positively skewed $\left(S_{K}=0.71,0.53\right.$ and 0.52 , for bar \#1 to \#3, 400 respectively), confirming water-worked gravel surfaces (Aberle and Nikora, 2006). 
401 Analysis of the bed-elevation distributions shows that the three patches are different 402 however, and certainly echoes the grain-size differences identified earlier (Figures 2 403 and 3). Previous studies observed relationships between $\sigma_{z}$ and grain size, generally 404 expressed as $D_{50}$ (Aberle and Nikora, 2006; Hodge et al., 2009a; Smart et al., 2004).

A

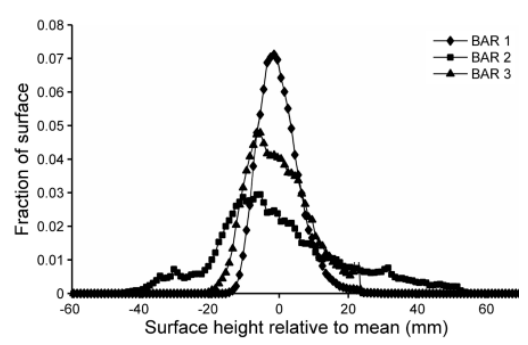

B

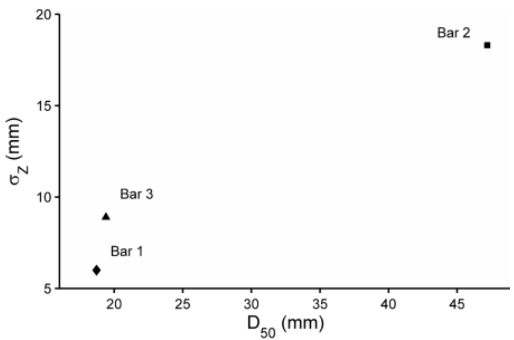

C

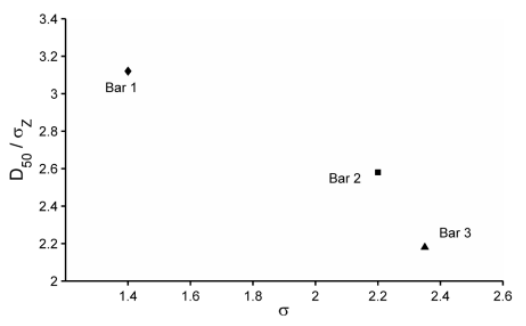

405 Figure 5. (A) Distributions of surface elevations for the three patches. Relationships 406 between $(B)$ the standard deviation of bed elevations $\left(\sigma_{\mathrm{Z}}\right)$ and the bed-surface $D_{50}$; 407 and $(C) D_{50} / \sigma_{z}$ and the sediment geometric sorting $(\sigma)$.

408 Here, bar \#1 had the smallest $D_{50}$ and the smallest $\sigma_{z}$, whilst bar \#2 had both the 409 largest $D_{50}$ and $\sigma_{z}$ (Figure $\left.5 \mathrm{~B}\right)$. However, the ratio of $\sigma_{z}$ to $D_{50}(0.32$ to 0.46$)$ varied 410 between patches, suggesting that $D_{50}$ is not the only factor determining $\sigma_{z}$, and other 411 factors such as sediment sorting are also responsible (Figure 5C). We found that the 412 ratio $D_{50} / \sigma_{z}$ decreases with the sediment sorting. This suggests that for similar 413 values of $D_{50}$, poorly-sorted sediments can create more irregular and rougher 414 surfaces, with accentuated grain packing, than well-sorted sediments, which agrees 415 with observations made by Hodge et al. (2009a).

416 Generalised second-order structure functions of (detrended) bed elevations were 417 calculated for all patches for lags up to $\pm 150 \mathrm{~mm}$ (corresponding to 3 to $8 \mathrm{D}_{50}$, 418 depending on the patch), being always larger than the maximum grain size and 419 enough to reach the saturation region, normalised by the saturation level $2 \sigma z^{2}$, and 


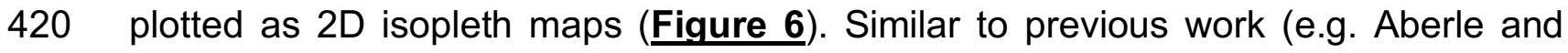

421 Nikora (2006)), we found that at small lags (up to $1 D_{50}$ ), the surface structure of the

422 gravel bars is isotropic, as shown by the circular contours in the centre of the 423 isopleth maps. The high correlation between pairs of points at small lags is because
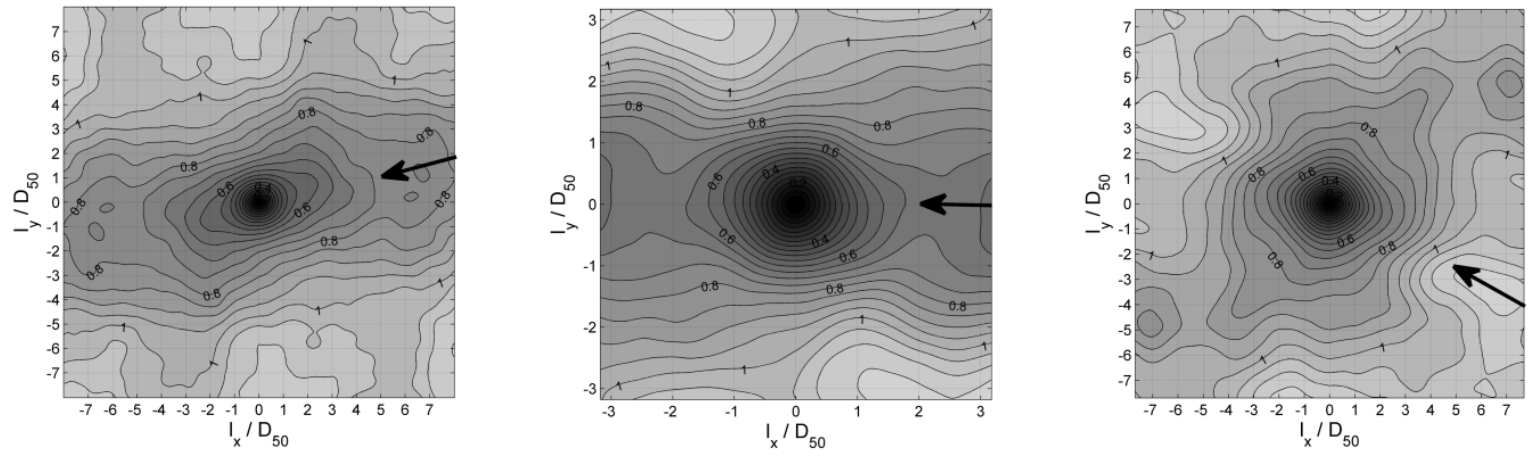

424 Figure 6. 2D isopleth maps of the generalised second-order structure functions for

425 the three patches (bar \#1 to \#3 from left to right). The assumed flow direction is 426 along the horizontal axis. Arrows show the most probable flow direction, based on

$427 \quad$ Figure 8.

428 the elevation pairs used to calculate the structure functions belong likely to the same 429 grain, and this suggests that small grains have no prevailing orientation. As the lag 430 increases, the contours generally become elliptical and supposedly reflect the 431 dominant grain orientation, with the long axis of the ellipse representing the a-axis 432 alignment (Hodge et al., 2009a; Nikora et al., 1998), until at large lags, equal to 2 to $4335 D_{50}$ depending on the patch, the contours become very irregular. Bar \#1 and bar \#2 434 both show a dominant grain orientation with the a-axis parallel to the flow direction. 435 For both patches, the streamwise correlations are stronger than the cross-flow 436 correlations, and remain strong over scales extending over the streamwise size of 437 the plots. This indicates gravelly structures longitudinal to the flow, a common 438 occurrence for water-worked gravel beds in both the laboratory and the field (Aberle 
439 and Nikora, 2006; Butler et al., 2001; Cooper and Tait, 2009; Hodge et al., 2009a;

440 Mao et al., 2011). This observation can be attributed to sediment deposition after

441 contact with the upstream front of a stable grain and particle imbrication. Bar \#3

442 presents a different shape of structure function for lags up to 2 to $3 D_{50}$. This may

443 reflect diamond-shape clusters (Aberle and Nikora, 2006; Mao et al., 2011), whose

444 extensive presence can be noticed on the ortho-image (Figure 3), unlike other 445 patches.

446 The combined distributions of DEM cell slope and aspect angles (Figure 7) show

447 that all three patches have a dominance of DEM cells with upstream aspects (i.e.

448 aspect angle around $0^{\circ}$ ). The latter is known to represent particle imbrication (Hodge

449 et al., 2009a), which naturally occurs in a direction parallel to the flow (Laronne and 450 Carson, 1976; Millane et al., 2006). Hence, bar \#2 certainly presented the highest 451 rate of surface imbricated grains. From the dominant slope angles in Figure 7, the 452 angle of imbrication is estimated at between $25^{\circ}$ and $50^{\circ}$ for all patches. The three 453 patches however present different grain arrangements at the bed surface. Bar \#1 is 454 characterised by DEM cell slopes rarely exceeding $70^{\circ}$ and particle imbrication not 455 as pronounced as on bar \#2. Bars \#2 and \#3 have DEM cells with slope angles sometimes reaching $80-90^{\circ}$, indicating more packed particles and rougher surfaces, 457 verifying previously presented observations (Figure 5). Bar \#3 shows imbrications 458 over a range of directions, from $0^{\circ}$ to $90^{\circ}$ with respect to the assumed flow direction. 459 Since imbrication is not centred on zero, which means that surface grains 460 predominantly imbricated in directions different from the flow direction, it might 461 suggest that the flow direction was incorrectly determined in the field. Concurrently, 462 imbricated particles covering a range of directions might say that the flow direction 463 changed over the duration of the last competent event, for example varied with flow 
depth, or that different flows (with different directions) imbricated particles in different
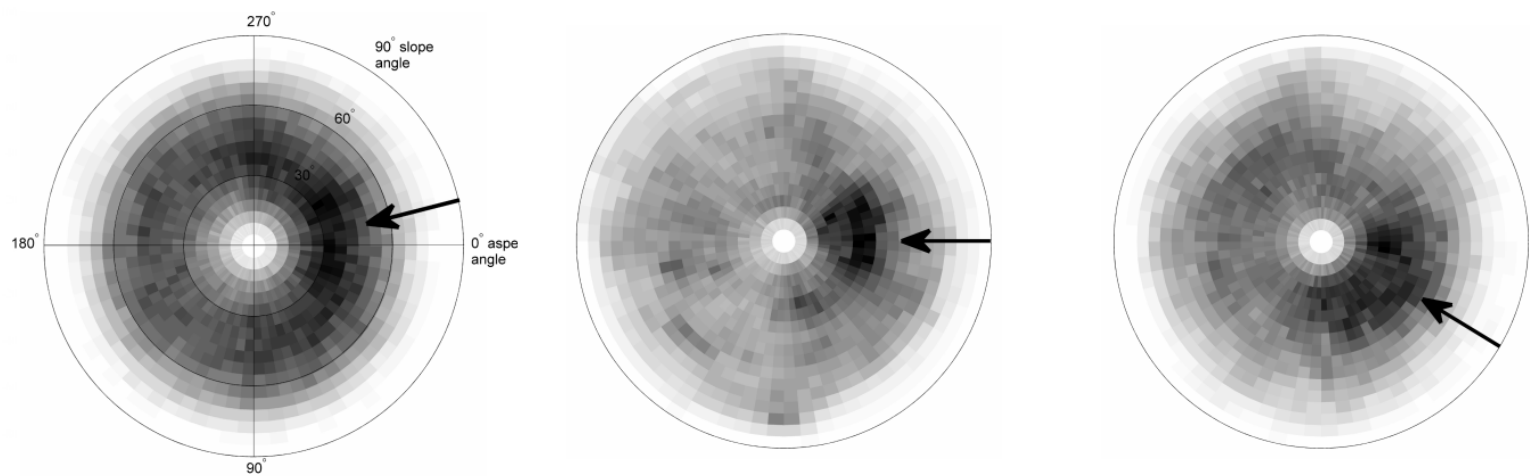

Figure 7. Polar plots of all $1 \mathrm{~mm}^{2}$ DEM grid cells aspect and slope angles for the three patches (bar \#1 to \#3 from left to right). Aspect angle is from $0^{\circ}$ to $360^{\circ}$ and slope angle is from $0^{\circ}$ to $90^{\circ}$; plots are shaded by point density (high density in black, zero density in white). The assumed flow direction is from $0^{\circ}$ to $180^{\circ}$. Arrows show the most probable flow direction, based on Figure 8.

Figure 8 shows the directional inclination indices calculated from the DEMs. Bar

472 \#2 shows the largest inclination index; hence, more of the patch area was covered 473 by imbricated particles than on the other patches. This corroborates observations 474 made on the combined distributions of DEM cell slope and aspect angles (Figure 7). 475 For bar \#2, the inclination index clearly peaks in the direction of the flow, suggesting 476 the flow direction was correctly determined in the field (Millane et al., 2006). Bar \#3 477 has an inclination index that plateaued for angles between approximately $0^{\circ}$ and $90^{\circ}$, 478 which again follows observations made previously on Figure 7. The maximum 479 inclination index for bar \#3 is attained for a DEM direction forming a $30^{\circ}$ angle with 480 the flow, suggesting that the assumed flow direction was erroneous by $30^{\circ}$ (Millane 481 et al., 2006). If this really is the case, the distribution of DEM cell slope and aspect 482 angles (Figure 7) for bar \#3, which initially differed from the other two patches, 
483 would have a more natural look and would exhibit a dominance of DEM cells with 484 upstream aspects, hence particle imbrication in the direction of the flow. Likewise, 485 this would affect the measured frequency-distribution of grains' a-axis orientation 486 (Figure 2B), which would then peak for angles perpendicular to the flow direction, 487 indicating a dominance of particles reposing across the flow; and the shape of the 488 2D structure function (Figure 6), which would also show a dominant ellipse 489 orientation transverse to the flow direction at medium lags. The latter two 490 observations demonstrate that more particles were aligned transverse to the flow on 491 bar \#3 than on the other patches, which can be associated with bedload transport 492 mode by rolling and sliding motion (Laronne and Carson, 1976). Bar \#1 shows a 493 smoother distribution of inclination indices, skewed to the left of the plot, which might 494 say that the actual surface-forming flow direction is slightly offset from the assumed 495 flow direction. Whilst this is not as clear as on bar \#3, this corroborates observations 496 made on Figures 6 and 7.

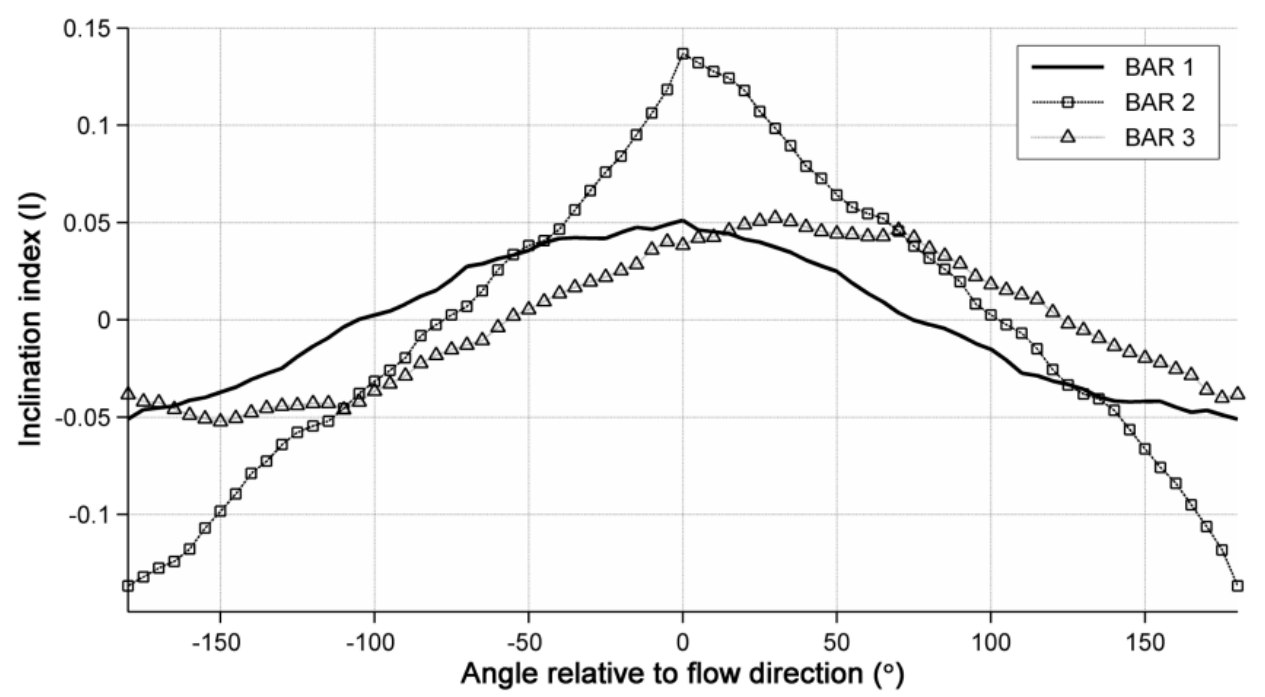

498 Figure 8. Directional inclination indices for the three patches. Inclination was 499 calculated for all angles between $-180^{\circ}$ and $180^{\circ}$ at a five-degree interval, using a 

distance, the lag for which imbrication was the most perceptible.

\section{Discussion}

503 We previously reported on our development of a non-proprietary CRDP technique, 504 making use of consumer-grade digital cameras and off-the-shelf calibration and 505 stereo matching engines, capable of recording gravel beds, water-worked in a 506 laboratory flume, at the grain scale, characterised by sub-millimetre DEM resolution 507 and accuracy (Bertin et al., 2015). We also showed that the same CRDP technique 508 can be used for through-water recording (Bertin et al., 2013). Here, we tested the 509 possibility to deploy the setup and adapt the methodology for measurements in a 510 natural river environment in the field.

\section{4.1. CRDP recommended measurement workflow and field potential}

512 Compared with previous fluvial applications of digital stereo photogrammetry, 513 calibration was performed in one go with a chequerboard, and did not require the 514 placement of fixed control targets on each patch, which in turn would require surveys 515 with a total station (or another independent device) for bundle adjustment. In addition 516 to speeding up data collection and limiting the resources needed on site, calibration 517 with a chequerboard prevents the introduction of additional errors due to the total 518 station, which adversely affects calibration, and hence DEM quality (Carbonneau et 519 al., 2003). It is noted, however, that having fixed control targets of known coordinates

520 (e.g. using a GPS tracker) (i) allows to place measured DEMs within a global 521 coordinate system, (ii) obviates the need to remove trend surfaces (see Section 2.4) and (iii) allows direct surface differencing in sequential surveys, which, however, is 523 deemed unnecessary for small-scale DEMs. For this field work, the application of 
524 photogrammetry was rendered even more effective by doing the calibration in "ideal"

525 conditions in the laboratory, providing optimum calibration parameters, prior to 526 moving to the field. There are drawbacks to this method however. The cameras' 527 arrangement on the mounting bar, after calibration, needs to remain as unmodified 528 as possible until the gravel-bed images are collected, to guarantee representative 529 calibration parameters. Using a chequerboard allowed efficient and effective testing 530 of the calibration validity after transport to the field, which was confirmed in this 531 study. Moreover, a laboratory calibration requires pre-supposition of the camera-to532 riverbed and baseline distances used in the field, both controlling the measurement 533 performance, and therefore limiting the applicability of the calibrated setup to a range 534 of tasks (microtopographic measurements herewith). With the large body of work on 535 the subject, it is well known that digital cameras are versatile instruments, able to 536 perform 3D measurements over a range of spatial scales, from microtopography to 537 channel shape (Butler et al., 2001; Javernick et al., 2014; Lane, 2000; Lane et al., 538 2003). The studied scale will depend on the application details. Our CRDP workflow 539 can accommodate various measurement scenarios: (i) several overlapping small540 scale DEMs can be merged together, producing a larger DEM that shares the 541 measurement quality of the original DEMs (Bertin et al., accepted for publication); (ii)

542 the CRDP setup can be adjusted and re-calibrated on site to suit larger-scale 543 measurements better (e.g. by increasing the baseline and camera distance); (iii) 544 more than one pre-calibrated setup can be transported to the field, each attributed a 545 specific task; and (iv) a camera can be detached to collect imagery from which 546 larger-scale DEMs are reconstructed using other methods than herewith presented 547 (e.g. SfM, (Javernick et al., 2014)). It is noted that novel SfM/MVS photogrammetric 548 techniques, using a single non-calibrated camera, may provide a viable alternative to 
549 classical stereo photogrammetry in measuring gravel patches at fine scales. Some 550 SfM/MVS pipelines are freely available (Stumpf et al., 2015). They are able to 551 generate data at high resolution (James and Robson, 2012) and can begin to tackle 552 the problem of occlusions since imagery is collected from different viewpoints. 553 However, SfM/MVS-generated DEMs may suffer from large non-linear distortions 554 due to inadequate lens distortion calibration (Fonstad et al., 2013; Ouédraogo et al., 555 2014), a drawback that has been resolved in traditional stereo photogrammetry 556 (Bertin et al., 2015; Wackrow and Chandler, 2008). Furthermore, a large number of 557 images (possibly hundreds) are necessary to reach DEM densities comparable to 558 the one required for this study, and will result in much longer processing time (James 559 and Robson, 2012).

In conjunction with accurate calibration, scanline-based pixel-to-pixel stereo matching adopted in this study resulted in dense DEMs, with the possibility to have a 562 DEM grid size as small as the pixel size at the riverbed's distance. This fact limited 563 surface smoothing and improved on traditional area-based methods, whereby the 564 smallest DEM grid size is chosen to be five times the pixel size on the surface (Lane 565 et al., 2000). Limited post-processing was applied on the DEMs, which was deemed 566 optional and prevented the introduction of new errors. For TLS applications, 567 measurement resolution can also be a limiting factor for DEM quality. Hodge et al. 568 (2009a; 2009b) reported using a laser-scanning system with a $4 \mathrm{~mm}$ footprint in a 569 field study measuring grain-scale fluvial morphology. A rigorous methodology was 570 necessary to maximise point coverage and density and to minimise the effect of the 571 oblique scan angles, by collecting data from two or three scanner positions around 572 each patch, registered together by simultaneously scanning a network of fixed 573 targets, and taking three repeat scans from each scanner position to minimise errors 
574 in the data. The reported turn-round time was approximately $25-30$ minutes per scan.

575 However, there was still the need of significant post-processing in the form of three

576 filters to obtain accurate metrics (Hodge et al., 2009a; Hodge et al., 2009b; Smith et 577 al., 2012).

578 A potential advantage of TLS over CRDP is its direct "time-of-flight" 579 measurement, compared with measurements relying on image quality and texture 580 (Hodge et al., 2009b). This certainly helped promoting the advent of range (also 581 called time-of-flight) cameras and usage in the Earth Sciences (Mankoff and Russo, 582 2013; Nitsche et al., 2013). However, a number of difficulties, including the need to 583 collect data in low-light conditions, currently limit the applicability of this recent 584 technology in the field and prevent accurate grain-scale data collection. Moreover, 585 surface reflectivity can introduce systematic time-of-flight measurement errors 586 (Hodge et al., 2009b; Nitsche et al., 2013), for which the only remedies are repeat 587 scan processing and filtering. In contrast, digital photogrammetry provides the 588 opportunity to optimise image collection (e.g. by varying the shutter speed), and use 589 image transformation techniques, such as Retinex, to improve stereo matching. This 590 proved to be a source of significant DEM accuracy improvement in the laboratory 591 (Bertin et al., 2015), and we expect this will become even more important in the field, 592 where lighting conditions are variable.

593 During this field work, we also tested the possibility to assess DEM quality 594 without ground check points and a total station. Data quality assessment, an 595 important component to every topographic survey (Lane et al., 2005), was performed 596 using a ground-truth object produced by 3D printing (Bertin et al., 2014). Due to the 597 small size of the 3D-printed model, we believe this assessment suits small-scale 598 DEMs well, but would not be adequate for larger DEMs. In addition to saving time on 
599 site, the use of a realistic ground truth provided a precise and reliable quantification

600 of DEM errors. This way, we showed that CRDP is capable of measuring complex 601 surfaces in the field with good vertical accuracy.

\section{4.2. Riverbed morphology and between-bar variations}

603 A range of methods was used to analyse the gravel-bed DEMs, some of which are 604 by now well-known to the Earth Science community (e.g. probability distribution 605 functions and generalised structure functions), and have been used extensively in 606 studies on the geomorphology of gravel-bed rivers over the past decades (e.g. 607 Robert (1991); Butler et al. (2001); Aberle and Nikora (2006)). Other methods 608 however, such as the combined distribution of DEM cells' slope and aspect angles 609 and the directional inclination index, have only been used in a handful of studies on 610 gravel-bed rivers so far (Hodge et al., 2009a; Millane et al., 2006; Qin et al., 2012). 611 Analysis of surface elevations (Fiqure 5) identified differences between the three 612 patches, and showed that both the median grain size $\left(D_{50}\right)$ and sediment sorting $(\sigma)$ 613 exert control on the surface irregularity and geometric roughness after water-work, 614 with the geometric roughness represented by the standard deviation of bed 615 elevations $\left(\sigma_{z}\right)$. The bed-elevation distribution skewness $\left(S_{K}\right)$, positive for all bars, 616 confirmed that the patches comprised water-worked gravels (Aberle and Nikora, 617 2006). Information derived from the 2D structure functions was useful to identify 618 variations on the size, orientation and type of gravel structures found on the gravel 619 bars. Bars \#1 and \#2 had longitudinal gravel structures, extending over lengths 620 several times the surface $D_{50}$. Diamond-shaped clusters were observed on bar \#3, 621 which was evidenced in the 2D isopleth maps (Figure 6). There was a good 622 agreement between the prevailing grain orientation determined using either the 623 structure functions or grain delineation in the photographs (Figure 2B). However, 
624 this failed at being conclusive on the surface-forming flow direction (Hodge et al., 625 2009a). The latter is notoriously difficult to determine accurately from visual 626 observations in the field (e.g. Smart et al. (2004)). Using DEMs has improved means 627 to determine the antecedent flow direction from measurements of exposed gravel 628 surfaces, especially when relying on surface inclinations (Aberle and Nikora, 2006; 629 Millane et al., 2006; Smart et al., 2004). In this study, analyses of the directional 630 inclination index (Figure 8) and the combined distribution of DEM cell slope and 631 aspect angle (Figure 7) reached the same conclusion on particle imbrication, hence 632 surface-forming flow direction(s). Bar \#2 was the patch with most of its surface 633 covered with imbricated particles (Figure 8). The neat imbrication in a single 634 direction confirmed the flow direction determined in the field. Bars \#1 and \#3 635 presented imbricated particles over a range of directions, suggesting flow direction 636 changed over the last flow event(s) and imbricated particles in different ways. 637 Plotting the directional inclination index has the advantage of clearly showing the 638 angle(s) for which imbrication is the most significant (Millane et al., 2006), hence the 639 surface-forming flow direction(s). Surface slope and aspect is hardly 640 parameterisable, but provides information on the angles with which sediment 641 particles repose at the surface.

642 As Rice and Church (2010) pointed out, focus in past research has been on bed643 material grain size variation in gravel-bed rivers at reach and river-length scales, and 644 has sought to explain the principal features, including downstream fining and the 645 gravel-sand transition. Relatively little information is currently available on the 646 variations in surface structure and geometric roughness, despite that we know that 647 these factors influence flow resistance and sediment transport (Church et al., 1998; 648 Komar and Li, 1986; Laronne and Carson, 1976), and may be used to explain the 
649 processes responsible for the formation and evolution of sedimentary units, such as 650 riffles and pools (Hodge et al., 2013). As shown in the presented study, field 651 deployment of remote-sensing techniques, such as CRDP, is becoming easier, and 652 statistical analysis of the DEMs has the potential to provide important information on 653 the variations in surface structure.

\section{5. Conclusion}

655 Collecting information on gravel-bed rivers at the grain scale in both the laboratory 656 and the field, although technically and methodologically challenging, is important for 657 applications such as roughness studies, sediment transport and the interactions 658 between animals and the geomorphology, topics relevant to many river practitioners.

659 Sediment size and 3D arrangement at the riverbed surface are all useful information 660 to collect; these factors control physical processes such as the resistance to the flow, 661 the ability of the flow to entrain sediment and create sediment structures, which in 662 turn can explain the existence of distinct sedimentary units within a river reach, and 663 the large-scale evolution of river basins.

664 Along with TLS, CRDP is a mature remote-sensing technique, theoretically 665 capable of high-spatial point density and accuracy, necessary for precisely 666 measuring gravel-bed microtopography. Despite extensive applications in the Earth 667 Sciences, both techniques suffer from a tedious measuring workflow when it comes 668 to measure fluvial sediment at the grain scale, which currently hinders the general 669 applicability of these techniques in the field, and in spite of the best of 670 methodological efforts, may not always guarantee reliable findings based on the 671 measured DEMs. 
672 This study presented how CRDP can be efficiently deployed in the field to collect

673 high-resolution and high-accuracy DEMs from exposed gravel bars. The only

674 resources needed were two digital cameras mounted on a rigid bar, two tripods and

675 a laptop. Field data collection was greatly simplified by undertaking the necessary

676 calibration in the laboratory, prior to moving to the field. This removed the need to 677 deploy ground-control targets. Dense stereo matching and image optimisation 678 helped the collection of DEMs without being impacted by variable lighting conditions, 679 which challenge applications of TLS and range imaging. A light-weight 3D-printed 680 model, resembling a water-worked gravel bed, was used on site as a ground-truth 681 object to assess the accurate measurement of elevation data. In this work, DEMs 682 were collected at a $1 \mathrm{~mm}$ sampling distance, which could go as low as the pixel size 683 at the riverbed's distance (i.e. around $0.25 \mathrm{~mm}$ ), with a measured accuracy of 0.67 $684 \mathrm{~mm}$ (based on MUE), which guaranteed reliable grain roughness properties from the 685 DEMs.

686 A variety of statistical methods was applied to the DEMs and identified between687 bar sedimentological contrasts. Analysis of the distribution of surface elevations 688 confirmed that the surfaces were water-worked (positive distribution skewness) and allowed ranking the patches by their geometrical roughness $\left(\sigma_{z}\right)$. It showed how $\sigma_{z}$ is 690 influenced by both the median grain size $\left(D_{50}\right)$ and sediment sorting $(\sigma)$. Information 691 derived from the 2D structure functions helped identify variations in size, orientation 692 and type of gravel structures found on the gravel bars. Bars \#1 and \#2 both had 693 longitudinal gravel structures, which contrasted with the diamond-shaped clusters 694 found on bar \#3. The prevailing grain orientation determined from automatically 695 delineated grains in the photographs supported observations from the 2D structure 696 functions, but failed at being conclusive on the surface-forming flow direction. For the 
697 latter, analyses of the directional inclination index and the combined distribution of

698 DEM cell slope and aspect angle were the most helpful, showing the direction(s) of 699 particle imbrication, hence the surface-forming flow direction(s).

700 Continuous progress in topography remote sensing is important to extend our

701 fluvial knowledge, for example by allowing the study of flow-channel processes at 702 different scales, in both space and time. Better characterisation of these processes 703 in situ, with the efficient and effective measurement of submerged surfaces, is a 704 critical task that needs to be tackled in future, ultimately to develop a technique 705 customised for use by fluvial geomorphologists in the field.

\section{References}

707 Aberle, J. and V. Nikora 2006. Statistical properties of armored gravel bed surfaces. 708 Water Resources Research 42: W11414.

709 Aberle, J. and G. M. Smart 2003. The influence of roughness structure on flow 710 resistance on steep slopes. Journal of Hydraulic Research 41: 259-269.

711 Bertin, S. and H. Friedrich Submitted. Stable fluvial armors and surface structure 712 replicability. Water Resources Research.

713 Bertin, S., H. Friedrich and P. Delmas accepted for publication. A merging solution 714 for close-range DEMs to optimise surface coverage and measurement resolution. $715 \quad$ Photogrammetric Engineering \& Remote Sensing.

716 Bertin, S., H. Friedrich, P. Delmas and E. Chan 2013. The use of close-range digital 717 stereo-photogrammetry to measure gravel-bed topography in a laboratory 718 environment, Proceedings of the 35th IAHR Congress, Chengdu, China: 719 unpaginated CD-ROM 
720 Bertin, S., H. Friedrich, P. Delmas, E. Chan and G. Gimel'farb 2014. DEM quality 721 assessment with a 3D printed gravel bed applied to stereo photogrammetry. 722 Photogrammetric Record 29: 241-264.

723 Bertin, S., H. Friedrich, P. Delmas, E. Chan and G. Gimel'farb 2015. Digital stereo 724 photogrammetry for grain-scale monitoring of fluvial surfaces: Error evaluation 725 and workflow optimisation. ISPRS Journal of Photogrammetry and Remote $726 \quad$ Sensing 101: 193-208.

727 Bird, S., D. Hogan and J. Schwab 2010. Photogrammetric monitoring of small 728 streams under a riparian forest canopy. Earth Surface Processes and Landforms 729 35: 952-970.

730 Bouguet, J.-Y. 2010. http://www.vision.caltech.edu/bouguetj/calib doc/. (last date $731 \quad$ accessed: 1st July 2014)

732 Bouratsis, P., P. Diplas, C. L. Dancey and N. Apsilidis 2013. High-resolution 3D 733 monitoring of evolving sediment beds. Water Resources Research 49: 977-992.

734 Bradley, D. and W. Heidrich 2010. Binocular camera calibration using rectification 735 error, Proceedings of the 2010 Canadian Conference on Computer and Robot 736 Vision (CRV), Ottawa, Ontario, Canada: 183-190

737 Butler, J. B., S. N. Lane and J. H. Chandler 1998. Assessment of DEM quality for 738 characterizing surface roughness using close range digital photogrammetry. 739 Photogrammetric Record 16: 271-291.

740 Butler, J. B., S. N. Lane and J. H. Chandler 2001. Characterization of the structure of 741 river-bed gravels using two-dimensional fractal analysis. Mathematical Geology $742 \quad 33: 301-330$. 
743 Butler, J. B., S. N. Lane, J. H. Chandler and E. Porfiri 2002. Through-water close range digital photogrammetry in flume and field environments. Photogrammetric $745 \quad$ Record 17: 419-439.

746 Carbonneau, P. E., S. N. Lane and N. E. Bergeron 2003. Cost-effective non-metric 747 close-range digital photogrammetry and its application to a study of coarse gravel $748 \quad$ river beds. International Journal of Remote Sensing 24: 2837-2854.

749 Chandler, J., J. Fryer and A. Jack 2005. Metric capabilities of low-cost digital 750 cameras for close range surface measurement. Photogrammetric Record 20: 1226.

752 Church, M., M. A. Hassan and J. F. Wolcott 1998. Stabilizing self-organized 753 structures in gravel-bed stream channels: Field and experimental observations. Water Resources Research 34: 3169-3179.

755

Cooper, J. R. and S. J. Tait 2009. Water-worked gravel beds in laboratory flumes - a 756 natural analogue? Earth Surface Processes and Landforms 34: 384-397.

757 Detert, M. and V. Weitbrecht 2012. Automatic object detection to analyze the 758 geometry of gravel grains, Proceedings of the River Flow 2012, San Jose, Costa $759 \quad$ Rica (Taylor and Francis Group): 595-600

760 Dowling, T. I., A. Read and J. C. Gallant 2009. Very high resolution DEM acquisition 761 at low cost using a digital camera and free software, Proceedings of the 18th 762 763 World IMACS Congress and MODSIM09 International Congress on Modelling and Simulation Cairns, Australia: pp. 2479-2485

764 Du Preez, C. and V. Tunnicliffe 2012. A new video survey method of 765 microtopographic laser scanning (MiLS) to measure small-scale seafloor bottom 766 roughness. Limnology and Oceanography: Methods 10: 899-909. 
767 Entwistle, N. S. and I. C. Fuller 2009. Terrestrial Laser Scanning to Derive Surface 768 Grain Size Facies Character of Gravel Bars. In Laser Scanning for the 769 Environmental Sciences (eds). Wiley-Blackwell; 102-114

770 Fehr, R. 1987. Geschiebeanalysen in Gebirgsflüssen translated Analysis of 771 Sedimentary Bed Material in Mountain Rivers. Conversion and Comparison of 772 Various Analytical Methods. Mitteilungen derVersuchsanstalt fürWasserbau, 773 Hydrologie und Glaziologie, Eidgenössische Technische Hochschule, Zürich Nr. $77492,1987$.

775 Fonstad, M. A., J. T. Dietrich, B. C. Courville, J. L. Jensen and P. E. Carbonneau 776 2013. Topographic structure from motion: a new development in 777 photogrammetric measurement. Earth Surface Processes and Landforms 38: $778 \quad 421-430$

779 Gimel'farb, G. 2002. Probabilistic regularisation and symmetry in binocular dynamic 780

781 Graham, D. J., A. J. Rollet, H. Piégay and S. P. Rice 2010. Maximizing the accuracy 782 of image-based surface sediment sampling techniques. Water Resources 783 Research 46: W02508.

784 Hannam, M. and M. L. Moskal 2015. Terrestrial Laser Scanning Reveals Seagrass 785 Microhabitat Structure on a Tideflat. Remote Sensing 7: 3037-3055.

786 Hauer, C., G. Unfer, P. Holzapfel, M. Haimann and H. Habersack 2014. Impact of 787 channel bar form and grain size variability on estimated stranding risk of juvenile 788 brown trout during hydropeaking. Earth Surface Processes and Landforms 39: 789 1622-1641.

790 Heritage, G. L. and D. J. Milan 2009. Terrestrial Laser Scanning of grain roughness 791 in a gravel-bed river. Geomorphology 113: 4-11. 
792 Hodge, R., J. Brasington and K. Richards 2009a. Analysing laser scanned digital 793 terrain models of gravel bed surfaces: linking morphology to sediment transport 794 processes and hydraulics. Sedimentology 56: 2024-2043.

795 Hodge, R., J. Brasington and K. Richards 2009b. In situ characterization of grain796 scale fluvial morphology using Terrestrial Laser Scanning. Earth Surface $797 \quad$ Processes and Landforms 34: 954-968.

798 Hodge, R. A., D. A. Sear and J. Leyland 2013. Spatial variations in surface sediment 799 structure in riffle-pool sequences: a preliminary test of the Differential Sediment 800 Entrainment Hypothesis (DSEH). Earth Surface Processes and Landforms 38: $801 \quad 449-465$.

802 James, M. R. and S. Robson 2012. Straightforward reconstruction of 3D surfaces 803 and topography with a camera: Accuracy and geoscience application. Journal of $804 \quad$ Geophysical Research: Earth Surface 117: n/a-n/a.

805 James, T. D., P. E. Carbonneau and S. N. Lane 2007. Investigating the effects of 806 DEM error in scaling analysis. Photogrammetric Engineering \& Remote Sensing $807 \quad 73: 67-78$.

808 Javernick, L., J. Brasington and B. Caruso 2014. Modeling the topography of shallow 809 braided rivers using Structure-from-Motion photogrammetry. Geomorphology $810 \quad$ 213: 166-182.

811 Komar, P. D. and Z. Li 1986. Pivoting analyses of the selective entrainment of 812 sediments by shape and size with application to gravel threshold. Sedimentology $813 \quad 33: 425-436$.

814 Lane, S. N. 2000. The measurement of river channel morphology using digital 815 photogrammetry. Photogrammetric Record 16: 937-961. 
816 Lane, S. N., T. D. James and M. D. Crowell 2000. Application of digital 817 photogrammetry to complex topography for geomorphological research. 818 Photogrammetric Record 16: 793-821.

819 Lane, S. N., S. C. Reid, R. M. Westaway and D. M. Hicks 2005. Remotely sensed 820 topographic data for river channel research: the identification, explanation and 821 management of error. In Spatial Modelling of the Terrestrial Environment (eds). 822 John Wiley \& Sons, Ltd; 113-136

823 Lane, S. N., R. M. Westaway and D. Murray Hicks 2003. Estimation of erosion and 824 deposition volumes in a large, gravel-bed, braided river using synoptic remote 825 sensing. Earth Surface Processes and Landforms 28: 249-271.

826 Laronne, J. B. and M. A. Carson 1976. Interrelationships between bed morphology 827 and bed-material transport for a small, gravel-bed channel. Sedimentology 23: 828 67-85.

829 Mankoff, K. D. and T. A. Russo 2013. The Kinect: a low-cost, high-resolution, short830 range 3D camera. Earth Surface Processes and Landforms 38: 926-936.

831 Mao, L., J. R. Cooper and L. E. Frostick 2011. Grain size and topographical 832 differences between static and mobile armour layers. Earth Surface Processes 833 and Landforms 36: 1321-1334.

834 Millane, R. P., M. I. Weir and G. M. Smart 2006. Automated Analysis of Imbrication 835 and Flow Direction in Alluvial Sediments Using Laser-Scan Data. Journal of 836 Sedimentary Research 76: 1049-1055.

837 Nelson, P. A., W. E. Dietrich and J. G. Venditti 2010. Bed topography and the 838 development of forced bed surface patches. Journal of Geophysical Research: 839 Earth Surface 115: n/a-n/a. 
840 Nikora, V. I., D. G. Goring and B. J. F. Biggs 1998. On gravel-bed roughness $841 \quad$ characterization. Water Resources Research 34: 517-527.

842 Nitsche, M., J. M. Turowski, A. Badoux, D. Rickenmann, T. K. Kohoutek, M. Pauli 843 and J. W. Kirchner 2013. Range imaging: a new method for high-resolution 844 topographic measurements in small- and medium-scale field sites. Earth Surface $845 \quad$ Processes and Landforms 38: 810-825.

846 Ouédraogo, M. M., A. Degré, C. Debouche and J. Lisein 2014. The evaluation of 847 unmanned aerial system-based photogrammetry and terrestrial laser scanning to 848 generate DEMs of agricultural watersheds. Geomorphology 214: 339-355.

849 Qin, J., D. Zhong, G. Wang and S. L. Ng 2012. On characterization of the imbrication $850 \quad$ of armored gravel surfaces. Geomorphology 159-160: 116-124.

851 Rice, S. P. and M. Church 2010. Grain-size sorting within river bars in relation to 852 downstream fining along a wandering channel. Sedimentology 57: 232-251.

853 Rice, S. P., M. F. Johnson and I. Reid 2012. Animals and the Geomorphology of 854 Gravel-Bed Rivers. In Gravel-Bed Rivers (eds). John Wiley \& Sons, Ltd; 225-241 855 Rieke-Zapp, D. H., R. Rosenbauer and F. Schlunegger 2009. A photogrammetric 856 surveying method for field applications. Photogrammetric Record 24: 5-22.

857 Robert, A. 1991. Fractal properties of simulated bed profiles in coarse-grained 858 channels. Mathematical Geology 23: 367-382.

859 Rüther, N., S. Huber, S. Spiller and J. Aberle 2013. Verifying a photogrammetric 860 method to quantify grain size distribution of developed armor layers, Proceedings 861 of the 35th IAHR Congress, Chengdu, China: 7

862 Smart, G., J. Aberle, M. Duncan and J. Walsh 2004. Measurement and analysis of 863 alluvial bed roughness. Journal of Hydraulic Research 42: 227-237. 
864 Smith, M., D. Vericat and C. Gibbins 2012. Through-water terrestrial laser scanning 865 of gravel beds at the patch scale. Earth Surface Processes and Landforms 37: $866 \quad 411-421$.

867 Smith, M. W. and D. Vericat 2013. Evaluating shallow-water bathymetry from 868 through-water terrestrial laser scanning under a range of hydraulic and physical 869 water quality conditions. River Research and Applications.

870 Stumpf, A., J. P. Malet, P. Allemand, M. Pierrot-Deseilligny and G. Skupinski 2015. 871 Ground-based multi-view photogrammetry for the monitoring of landslide 872 deformation and erosion. Geomorphology 231: 130-145.

873 Verdú, J. M., R. J. Batalla and J. A. Martínez-Casasnovas 2005. High-resolution 874 grain-size characterisation of gravel bars using imagery analysis and geo875 statistics. Geomorphology 72: 73-93.

876 Wackrow, R. and J. H. Chandler 2008. A convergent image configuration for DEM 877 extraction that minimises the systematic effects caused by an inaccurate lens 878 model. Photogrammetric Record 23: 6-18.

879 Wackrow, R., J. H. Chandler and P. Bryan 2007. Geometric consistency and stability 880 of consumer-grade digital cameras for accurate spatial measurement. 881 Photogrammetric Record 22: 121-134.

882 883 